\title{
Compact Multi Reflection Cells for Optical Gas Sensor Applications
}

\author{
J. Herbst, B. Scherer, M. Steffen, B. Halford, Armin Lambrecht \\ Fraunhofer IPM, Heidenhofstr. 8, 79110 Freiburg
}

Johannes.herbst@ipm.fraunhofer.de

\begin{abstract}
Measuring low gas concentrations with absorption spectroscopy requires long optical paths in order to obtain sufficient detection limits. For low quantities of gas or a high temporal resolution the volume of the measurement cell should be as small as possible. This is the only way to guarantee an efficient, rapid gas exchange. A gas cell setup with a mirror configuration for multiple reflection allows keeping the dimensions of the cell low and, at the same time, ensures a long optical path.

Fraunhofer IPM develops compact and robust multi reflection gas measurement cells with optical path lengths between $1.6-15 \mathrm{~m}$ for scientific and industrial applications. There are two cell types with different mirror configurations. First the Herriott cell [1] consist of two opposed spherical mirrors, the White cell [2] of three. (Fig.1, 2)

In the framework of the BMBF project NOSE a Herriott gas cell for an optical, compact, cost effective and sensitive $\mathrm{O} 2$ and $\mathrm{CO}$ gas sensor is realized (Fig. 3). This cell has a volume of $40 \mathrm{ml}$ and $5 \mathrm{~m}$ optical pathway and is used for oxygen measurements. The absorption of the oxygen line at $763.84 \mathrm{~nm}$ is measured by tuneable diode laser spectroscopy (TDLS). A Vertical Cavity Surface Emitting Laser (VCSEL) scans the narrow wavelength range around the P9P9 line of the P-branch of the oxygen A-band transition. With this setup a noise equivalent concentration (NEC) of $6 \mathrm{ppm}$ in $1 \mathrm{~s}$ acquisition time is achieved. For another application a $15 \mathrm{~m}$-Herriott cell (Fig. 4) was developed for the detection of oxygen traces in an oxygen free atmosphere. Again the TDLS with VCSEL is used. The sensitivity is increased up to $2 \mathrm{ppm}$ NEC. The detection limit is determined by around 4 ppm oxygen.

Fraunhofer IPM develops filter photometers working in the mid-infrared to detect the gas in the fundamental vibration band. Theses bands show stronger line strength than the overtone vibrations in the near infrared. But in the mid infrared there are no cheap lasers available, so efficient IR-emitter are used. In this case it is more suitable to apply White cells as gas cells in a gas absorption measurement setup because the light sources is not point shaped like a laser. For instance a $1.6 \mathrm{~m}$ White cell (Fig. 6) in combination with an IR emitter is applied on ethylene measurements in the wavelength range of $10.6 \mu \mathrm{m}$ (Fig 5). The ethylene concentrations have to be measured and monitored during the food storage to control the fruit ripening. In the setup an IR-emitter, chopper, White cell and band pass filter in front of the pyrodector are used. The measured NEC is better than $25 \mathrm{ppm}$.
\end{abstract}

[1] J. U. White, Long paths of large aperture, J. Opt. Soc. Am. 32, 285 (1942)

[2] D. R. Herriot and J. H. Schulte, Folded optical delay lines, Appl. Opt. 4, 883, (1965) 

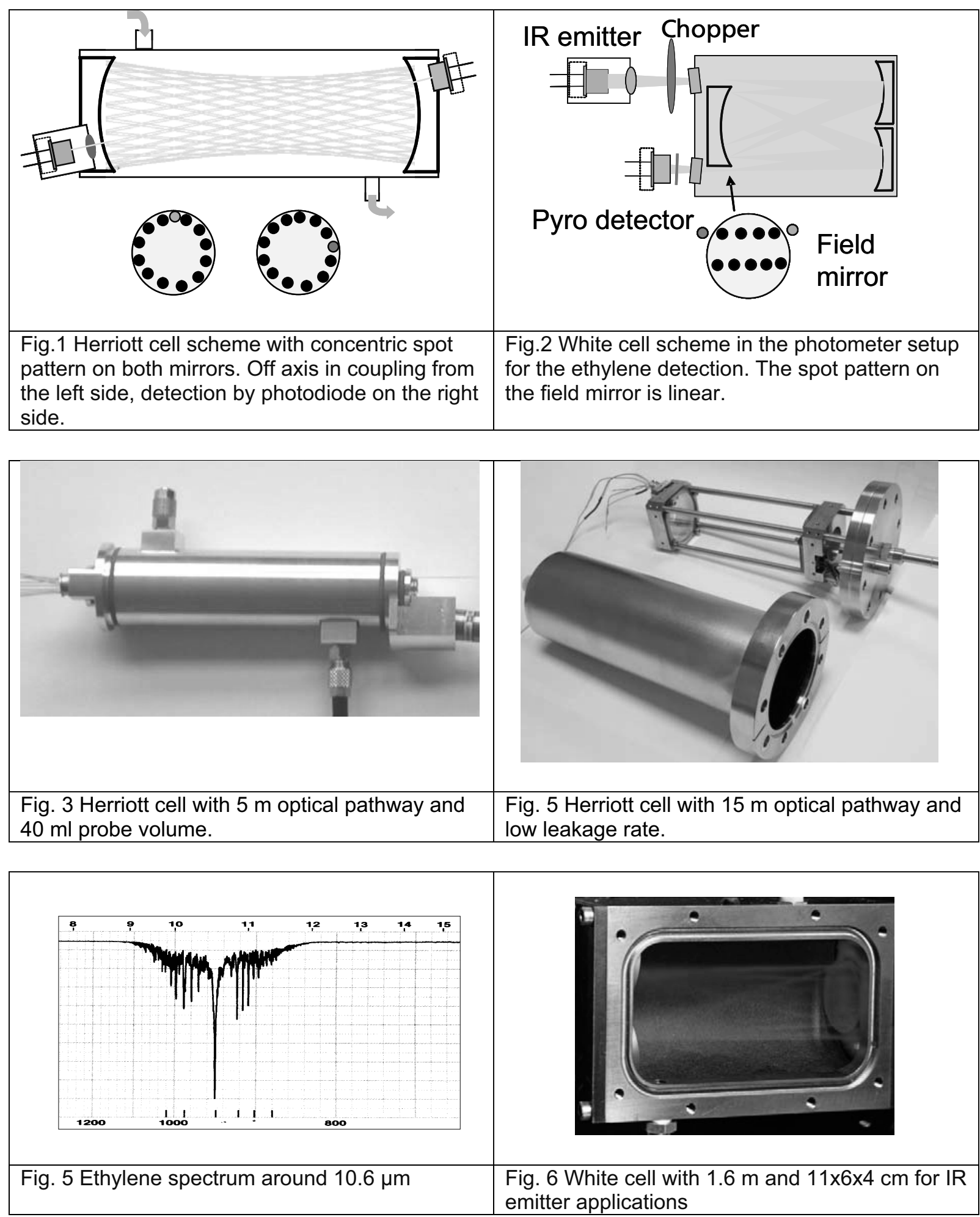